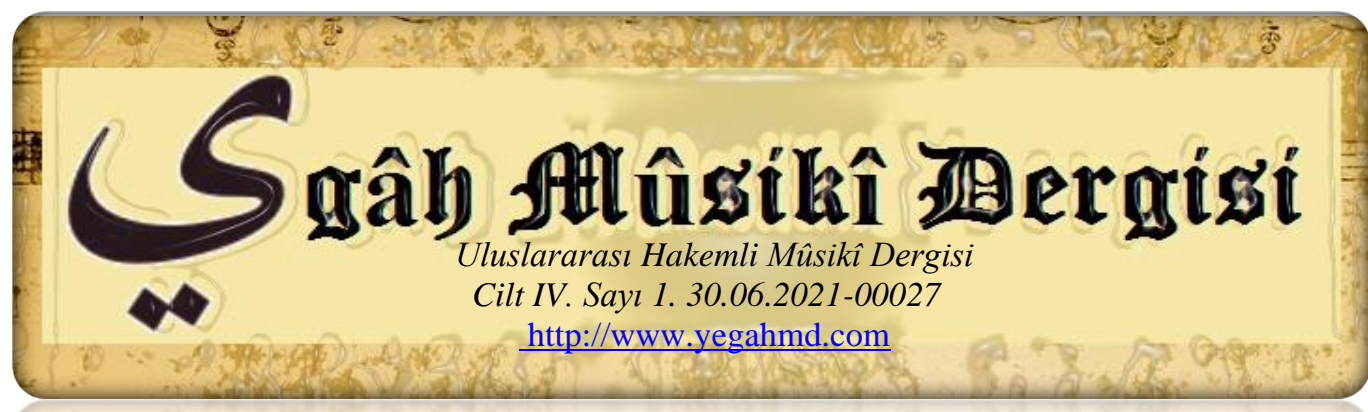

$\begin{array}{ll}\text { Makalenin Türü / Article Type } & : \text { Araştırma Makalesi / Researh Article } \\ \text { Geliş Tarihi / Date Received } & : 01.06 .2021 \\ \text { Kabul Tarihi / Date Accepted } & : 10.06 .2021 \\ \text { Yayın Tarihi / Date Published } & : 30.06 .2021 \\ \text { DOI } & : \underline{10.51576 / \text { yegah.946398 }} \\ \text { e-Issn } & : 2636-8838\end{array}$

İntihal/Plagiarism: Bu makale, en az iki hakem tarafından incelenmiş ve intihal içermediği teyit edilmiştir. / This article has been reviewed by at least two referees and confirmed to include no plagiarism.

\title{
GAGAUZ ÇALGILARINDAN KAUŞ
}

\author{
DELİGÖZ Atakan ${ }^{1}$
}

\section{ÖZ}

$\mathrm{Bu}$ makalede; Balkanlarda yaşayan Gagauzların kullandığı müzik aletlerinden biri olan kauş çalgısı ele alınmıştır. Üç telli olan ve icrası bir yay vasıtasıyla yapılan bu çalgı, fiziki yapı bakımından küçük ebatlı olmakla birlikte armudi şekillidir.

Kauş çalgısının genel durumunu tespit etmek için, 2012 yılında Moldova'nın Gagauz Özerk Yeri’nde saha çalışması yapılmış ve bu kapsamda farklı alanlardaki uzmanlar ve müzisyenler ile görüşülmüştür. Öte yandan müzelerde ve şahıslarda bulunan kauş çalgıları detaylı olarak incelenmiştir. Tespit edilen çalgıların üretiminde kullanılan malzemeleri, ebatları, formları ve icra biçimleri hakkında bilgiler edinilmiştir. Ayrıca elde edilen bilgiler doğrultusunda bu çalgının iki boyutlu genel teknik çizimi yapılmıştır. Böylece çalışmada kauşun ifade edilen bölümlerinin daha rahat anlaşılması sağlanmıştır.

Çalışmada, kauş çalgısının geçmişte yaygın olarak icra edildiği, 20. yüzyılda kullanımının giderek azaldığı ve günümüzde ise kaybolmaya yüz tuttuğu anlaşılmıştır. Öte yandan bu çalgının

\footnotetext{
${ }^{1}$ Dr. Öğr. Gör. Atakan DELİGÖZ, Ege Üniversitesi, D.T.M. Konservatuvarı Çalg1 Yapım ve Onarım Bölümü, İzmir, atakan_deligoz@hotmail.com, , (1) https://orcid.org/0000-0001-8295-7233
} 
çoğunlukla müzelerde yer aldığı görülmüştür. Böylece tarihsel ve kültürel açıdan ele alınarak incelenen kauş, yapısal özellikleri ve icra tarzı açısından belgelenmeye çalışılmıştır. Ayrıca çalgının yeniden kullanılır hale getirilmesi ve yaygınlaştırılması hususunda somut öneriler sunulmuştur.

Anahtar Kelimeler: Kauş, Gagauz Çalgıları, Gagauz.

\title{
KAUSH FROM GAGAUZ MUSICAL INSTRUMENTS
}

\begin{abstract}
In this article; Kaush, one of the musical instruments used by the Gagauz people living in the Balkans, is discussed. This three-stringed instrument, played by a bow, is small in size and pearshaped in terms of physical structure.

In order to determine the general condition of the kaush instrument, fieldwork was carried out in the Gagauz Autonomous Region of Moldova in 2012 and experts and musicians from different fields were interviewed. On the other hand, the kaush instruments found in museums and private individuals were examined in detail. Information was obtained about the materials used, sizes, forms and performances of the detected musical instruments. In addition, in line with the information obtained, a two-dimensional general technical drawing of this instrument was made. Thus, in the study, it was ensured that the expressed parts of the rubber were more easily understood.

In the study, it has been understood that the kaush instrument was widely performed in the past, its use gradually decreased in the 20th century and it is on the verge of disappearing today. On the other hand, it has been seen that this instrument is mostly found in museums. Thus, the kaush instrument, which has been examined from a historical and cultural point of view, has been tried to be documented in terms of its structural features and playing style. In addition, concrete suggestions have been put forward in terms of making the instrument usable again and making it widespread.
\end{abstract}

Keywords: Kaush, Gagauz musical instruments, Gagauz. 


\section{GíRiș}

Kauş, Balkanlarda yaşayan ve Türk topluluklarından biri olan Gagauzlar ${ }^{2}$ tarafindan icra edilen yaylı ve üç telli bir çalgıdır. Küçük ebatlı ve armudi formlu olan kauş (Fotoğraf 1) genellikle düğün ve şenliklerde davul, kaval ve çırtma (çığırtma) gibi çalgılarla beraber icra edilmiştir. Ayrıca vaftiz ve ad koyma törenlerinde de kullanılmıştır³.

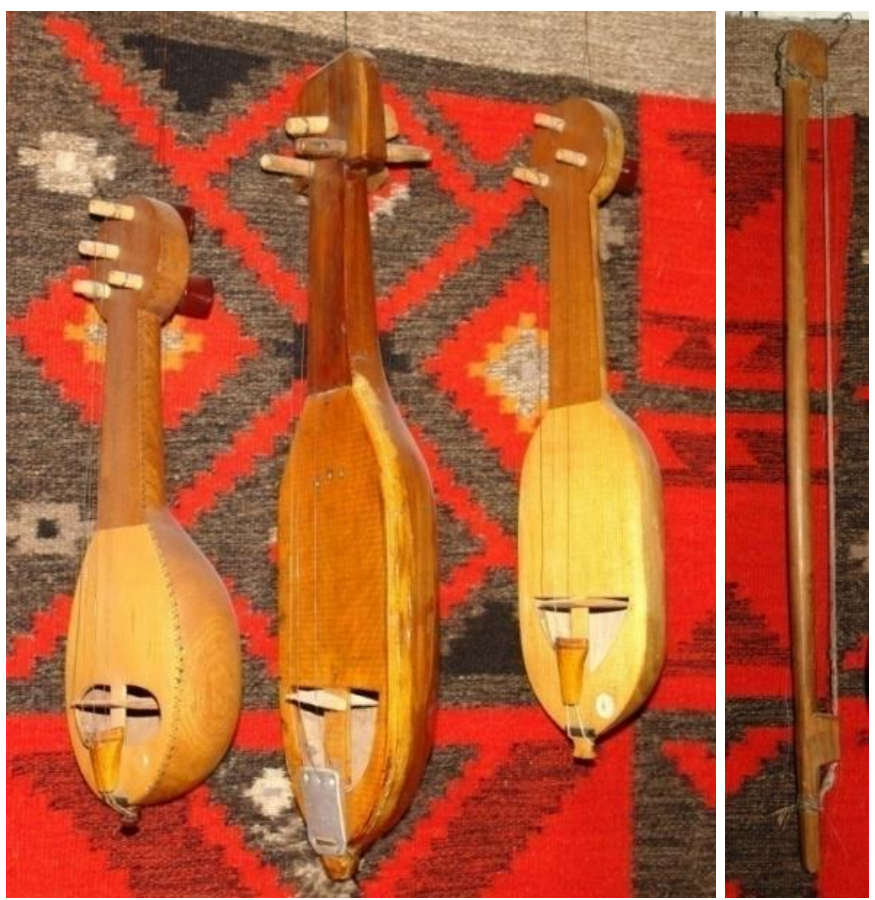

Fotoğraf 1. Kauş çalgıları ve yayı (Komrat Müzesi- Gagauz Özerk Bölgesi, Moldova).

Bu çalgının kaynaklarda kauşs (Karanfil, 2010:72), kauş-kemençe (Moşkov, 2004: 97), kavuş (Bulgar, 2004: 36), koğuş (Gazimihal, 1958: 66-67) ve kovuş (Gürdal, 2009) gibi farklı terimlerle ifade edildiği ve bu isimlerin kökenleri hususunda değiş̧ik görüşlerin bulunduğu görülmektedir ${ }^{4}$.

\footnotetext{
${ }^{2}$ Gagauzlar, Gagavuzlar ya da Gökoğuzlar olarak bilinen halk, bugün Moldova Cumhuriyeti’nin Gagauzeli Özerk Devletinde, kuzeydoğu Bulgaristan'da ve Ukrayna'da yaşayan, Hıristiyanlık inancına sahip olan bir Türk halkıdır. (http://tr.wikipedia.org/wiki/Gagauzlar erişim tarihi: 05.25.2021).

${ }^{3}$ Bu bilgiler 26 Ağustos-3 Eylül 2012 tarihleri arasında Gagauz Özerk Bölgesi'nde (Moldova) yapılan alan araştırmalarında Konstantin Ruşika ve İvan Kırım'dan derlenmiştir.

${ }^{4} \mathrm{Bu}$ çalgıya verilen isimler konusunda dil bilimci ve Türkolog olan Güllü Karanfil; kauş kelimesinin kov yani içi boş şey anlamındaki sözcükten türediğini (Karanfil, 2010: 75), araştırmacı ve tarihçi G. Stomatoglu; kopuzla ilgili olduğunu ve onun kobus-kovus-kovuş ve sonra kauş varyantına dönüştüğünü (Stamatoglu, 2002: 331), müzikolog Mahmut R. GAZIMİHAL'de G. Stomatoglu'na yakın bir görüşle koğuş kelimesinin kavuz-kopuz adını çağrıştırdığını ve bununla ilgili olabileceğini (Gazimihal, 1958: 66-67), araştırmacı ve müzisyen İrfan Gürdal ise; khovuz kelimesinin eski Türk dilinde kötü ruhları kovma anlamında olduğunu ve kavuş çalgısının isminin de bununla ilişkili olabileceğini ifade etmektedir (Gürdal, 2009).
} 
Gagauzlar tarafından çok eski zamanlardan beri icra edildiği bilinen ${ }^{5}$ kauş çalgısının adına, yazılı kaynaklarda dolaylı olarak ilk kez 15. yüzyılda rastlanmaktadır. 1470 yılına ait belgelerde BasarOba (Romanya) topraklarında Gagauzların yaşadığı Kauşan adında bir köyden söz edilmektedir. Araştırmacı ve tarihçi yazar Görgi Stomatoglu, köye verilen bu ismin orada yaşayan halkın kauş çalması ve yapmasından geldiğini ifade etmektedir (Stamatoglu, 2002: 319-321). Kauş çalgısı hakkında doğrudan bilgi veren yazılı kaynaklara gelince, bunların 19. yüzyıl sonu ve 20. yüzyıl başlarına ait olduğu görülmektedir. Bu konudaki ilk bilgiler 19. yüzyılın sonlarında Rus etnografı V. Moşkov'un yaptığı çalışma içerisinde yer almaktadır. V. Moşkov, Gagauz kültürünü araştırdığı ve yazdığı eserinde, şenliklerde yaygın olarak kemençe (keman), çırtma, kobza, kaval, kauşkemençe ve gayda gibi çalgıların kullanıldığını belirterek, bu çalgının ismini kauşkemençe olarak vermektedir (Moşkov, 2004: 179). Bu hususta bilgi veren bir diğer yazılı kaynakta Mihail Çakir (papaz) tarafından 20. yüzyılın başlarında yapılan ve Gagauz kültürü hakkında bilgi veren çalışmadır. Mihail Çakir kitabında çırtma (çığırtma), kaval, kemençe (keman), kobza, gayda ve kauş çalgılarından söz etmektedir (Çakir, 2007: 297).

Kauş çalgısının 20. yüzyılın başlarına kadar düğün ve eğlence gibi törenlerin başlıca ve önemli müzik aletlerinden birisi olduğu, yazılı kaynaklardan ve eski fotoğraflardan (Fotoğraf 2,5,7,8) anlaşılmaktadır. Ancak geçen yüzyıl başlarından itibaren değişen sosyokültürel yapı ve müzik anlayışı sebebiyle, söz konusu çalgının kullanımının giderek azaldığı görülmektedir. Bu hususa, Gagauzyalı müzik öğretmeni ve folklor araştırmacısı Veysel Arseven'in (Vasili Öküzcü 19191977) Şubat 1947 yılında Musiki Ansiklopedisi’nde yayınlanan makalesinde de değinilmiştir. Arseven, çalışmasında Gagauz çalgılarından söz ederken, kauşun eskiye göre daha az icra edildiğini belirtmiştir (Bulgar, 2004: 36). 20. yüzyılın ikinci yarısında ise güncel müzik ve orkestra içerisinde de kullanılmaya çalışılan çalgının (Fotoğraf 8) icrasının yaygınlaşması ve bunlar içerisinde yer etmesi pek mümkün olamamıştır. Günden güne kullanımı iyiden iyeye azalan kauş çalgısı, yakın dönemde Gagauzya'nın merkezi olan Komrat ve civarındaki en son icracılarından biri olan Stamatov Görgi Görgiviç’in ${ }^{6}$ (Fotoğraf 2, 8) 2004 yılında ölümüyle beraber, kaybolma yüz tutmuştur. Günümüzde Komrat’ta bu çalgıyı icra edenlere maalesef rastlanmamaktadır. Bu

\footnotetext{
${ }^{5}$ Bu bilgi 2012 tarihinde Gagauz Özerk Bölgesi’nde (Moldova) yapılan alan araştırmalarında Güllü Karanfil, Constantin Ruşika, Pioty Petkoviç, Topal Sergey ve G. Stomatoglu'ndan alınmıştır.

${ }^{6} 2012$ yılında Komrat’ta (Moldova-Gagauz Bölgesi) kauş icracısı Görgi Görgiviç Stamatov’un (1929 doğumlu) eşi Anna Görgivna Stamatova (1929 doğumlu) ile yapılan görüşmede, eşinin kauş çaldığı ve yaptığı ayrıca kauş yapımında elma, armut ve meşe gibi ağaçları kullandığı bilgileri alınmıştır.
} 
sebeple kauş çalgısı yalnızca müzelerde, özel koleksiyonlarda ve eski resimlerde görülebilmektedir (Fotoğraf 1-8). Geleneksel kültürün hızla değiştĭgi yakın dönem ve çağımız, Gagauz müziği ve çalgıları üzerinde değişimlere sebep olduğu ve bunun sonucunda da böyle üzücü sonuçların ortaya çıktığı görülmektedir.

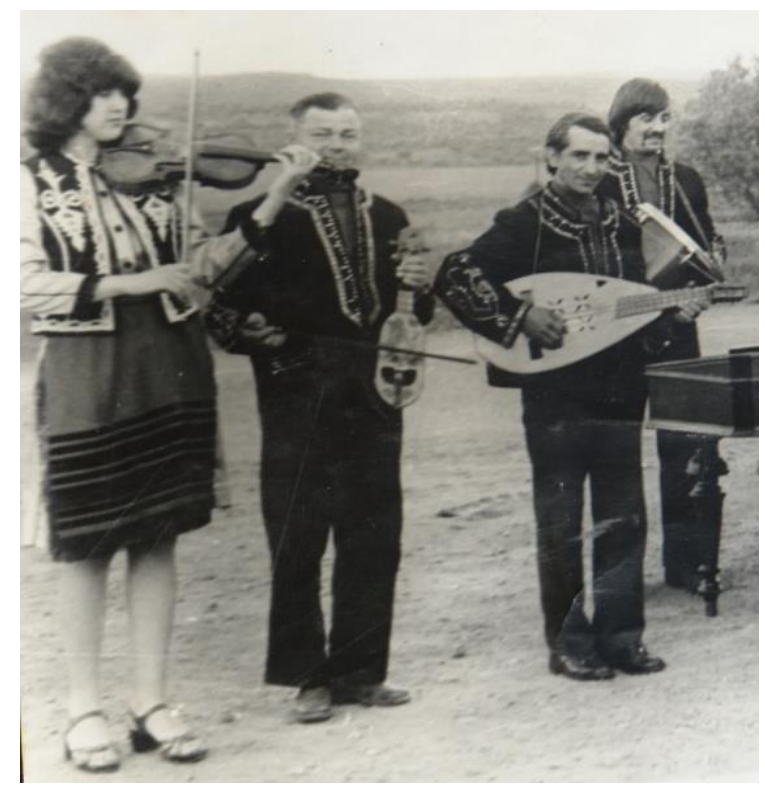

Fotoğraf 2. Kauş icracısı Görgi Görgiviç Stamatov (ortada) 1979, Komrat-Gagauz Özerk Bölgesi, Moldova.

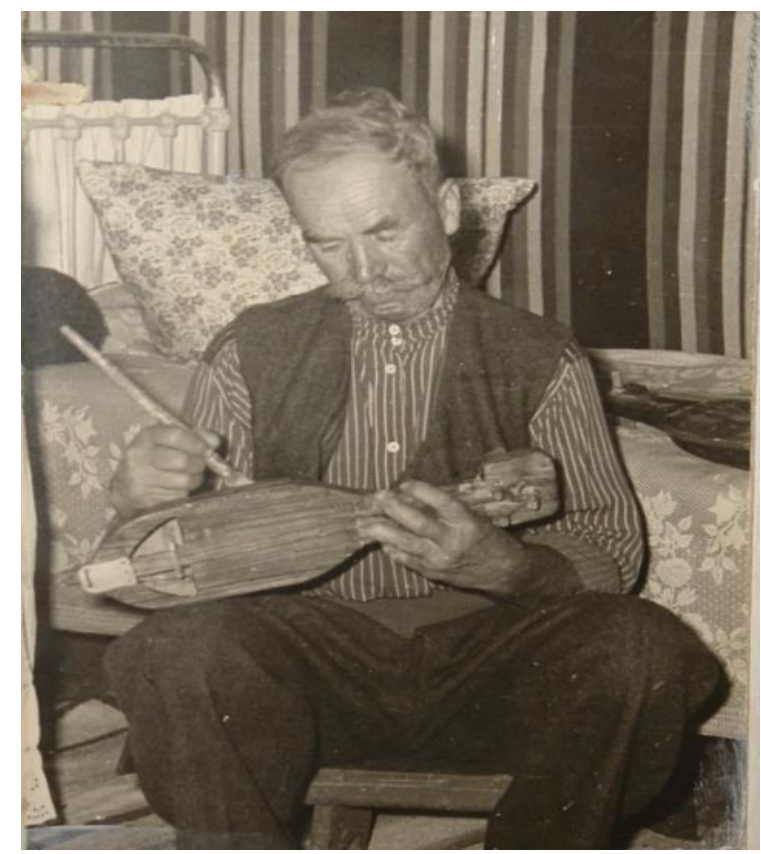

Fotoğraf 3. Kauş yapımcısı Dimitri Bolgar (1972-73 Yılı, Beşalma Müzesi-Komrat). 


\section{Kauş Çalgısının Fiziki Yapısı ve İcrası}

Günümüze ulaşan kauş çalgılarının fiziki yapısı incelendiğinde, bunların küçük ebatlı ve genellikle armudi formlu olduğu görülmektedir. Ortalama 40-55 cm arasında bir uzunluğa ve 11,5-14 cm arasında bir genişliğe sahip olan çalgının ölçüleri standart olmamakla beraber, yapan ustaya veya var olan malzemeye göre değişkenlik gösterebilmektedir ${ }^{7}$. Bundan dolayı mevcut kauş çalgılarının tel boyları da farklı ölçülerde olabilmektedir.

Geleneksel olarak üç ana bölümden (ses kutusu, sap ve burguluk) meydana gelen çalgının gövdesi tek parça (yekpare) ağaçtan oyularak yapılmaktadır (Çizim 1). Gövde yapımında genellikle dut, meşe, elma, armut ve ceviz gibi ağaçlar kullanılmaktadır. Bunların yanı sıra nadiren farklı ağaçlardan yapılan örneklere de rastlanabilmektedir.

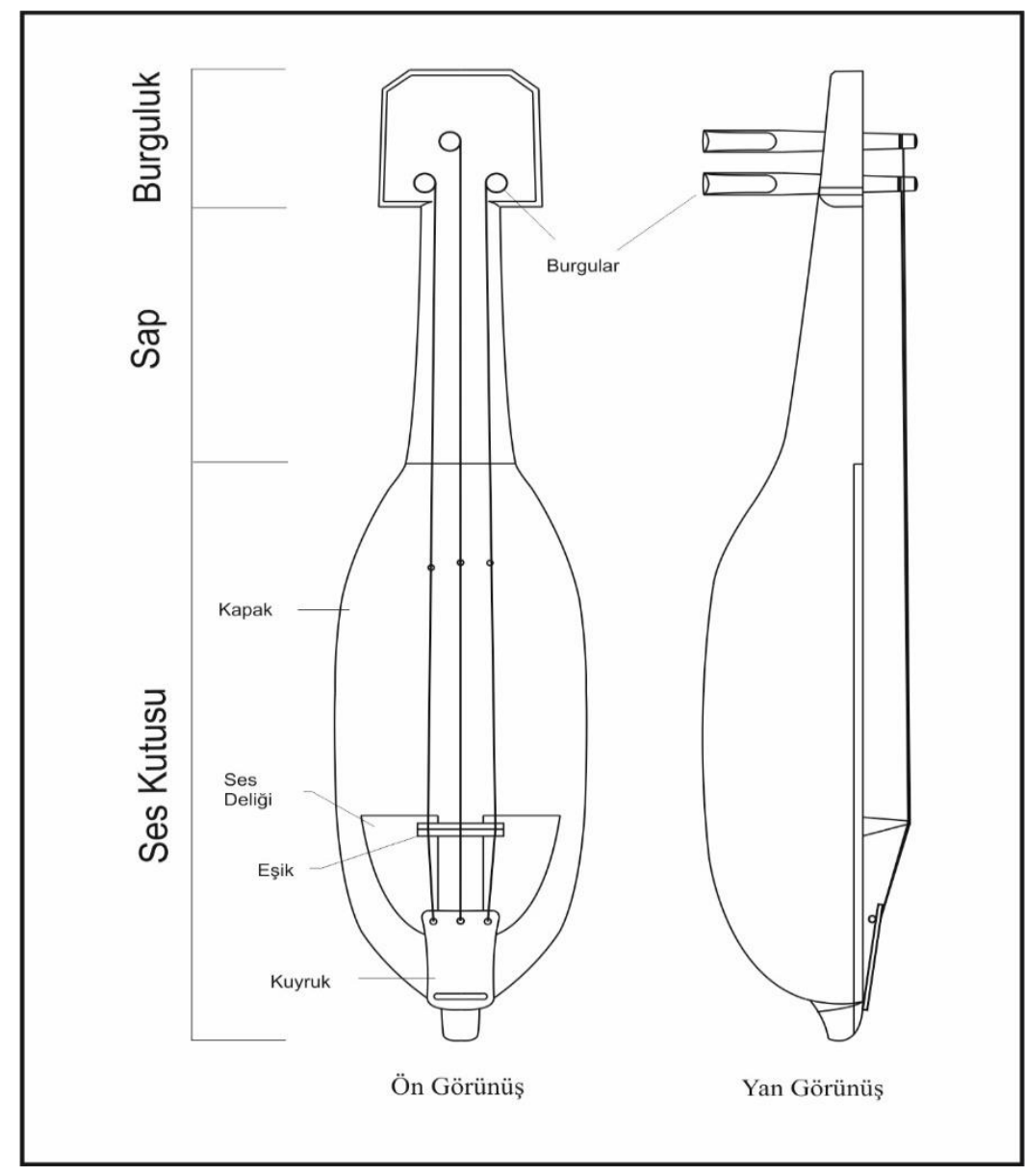

Çizim 1. Kauşun ön ve yan bölümleri ile detayları.

\footnotetext{
72012 tarihinde Moldova'nın Gagauz Bölgesinde yaptı̆̆ımız alan araştırmasında farklı ebatlarda kauşlara rastlanmış ve yukarıdaki ölçüler bu doğrultuda verilmiştir.
} 
Gövdenin alt kısmında yer alan ses kutusu bölümü, köşeli (Fotoğraf 4) ve yuvarlak hatlı olmak üzere farklı formlarda olabilmektedir (Fotoğraf 1,4). Arkaya doğru şişkin ve armudu formlu olan bu kısmın içerisi oyularak boşaltılmakta ve üzeri ahşap kapakla örtülmektedir. Kapak, 4-5 mm kalınlığındaki çam türü ağaçlardan (genellikle ladin ağacı) yapılmaktadır. Kapak üzerinde seslerin rahat bir şekilde dışarı çıkmasını sağlayan karşılıklı ve simetrik iki ses deliği bulunmaktadır. $\mathrm{Bu}$ deliklerin genellikle yarım veya çeyrek daire şekline yakın olduğu görülmektedir (Fotoğraf 6).

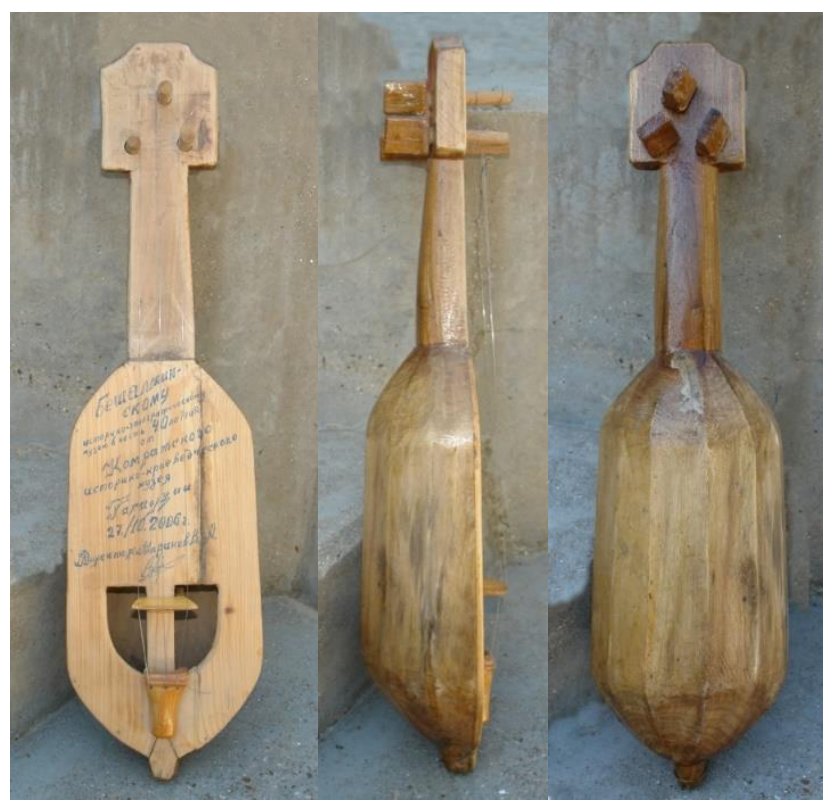

Fotoğraf 4. Kauş'un Ön, Yan ve Arka Görüntüsü (Beşalma Müzesi).

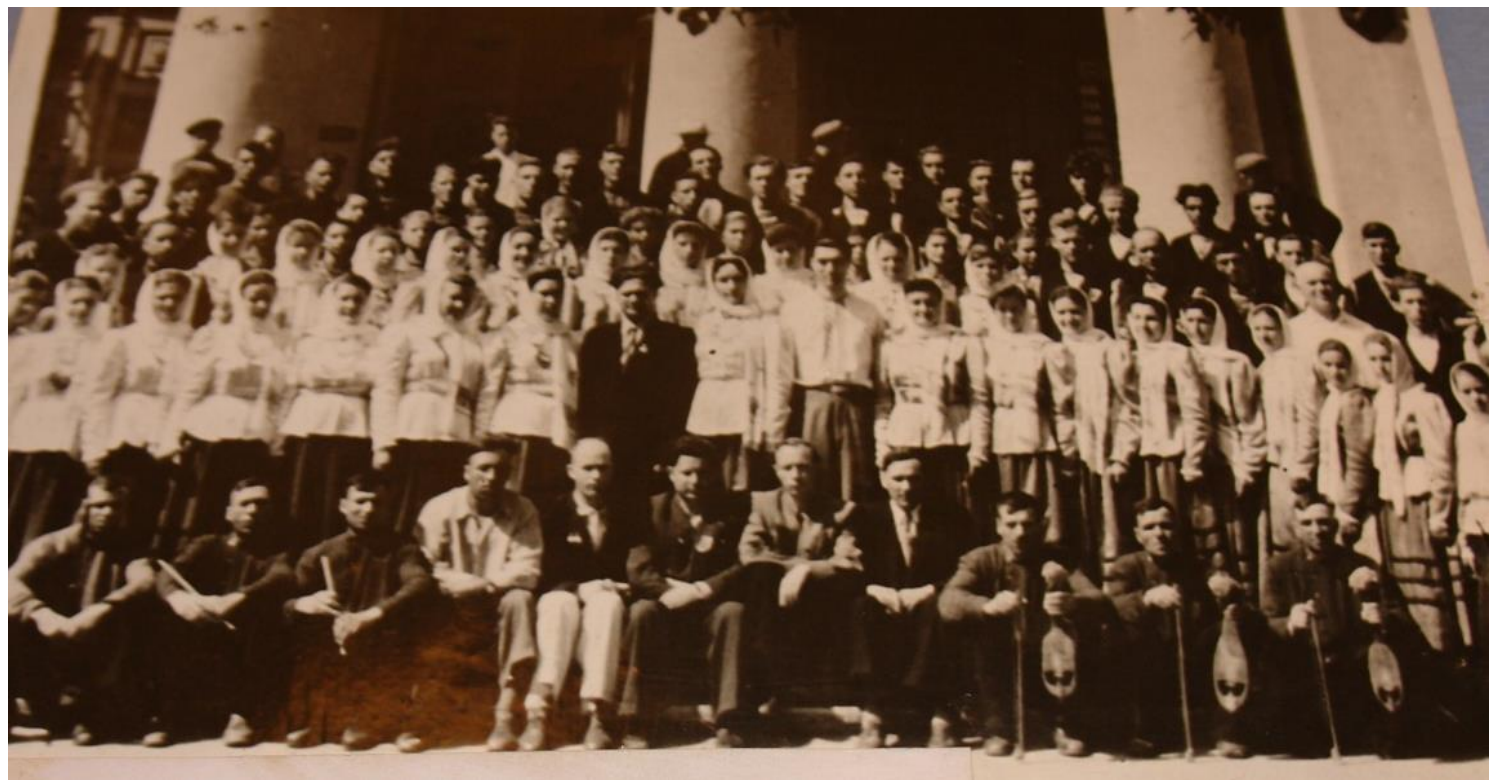

Fotoğraf 5. Farklı formlardaki kauşlar (Sağ alt köşede)- (1958 Yılı-Komrat Müzesi). 


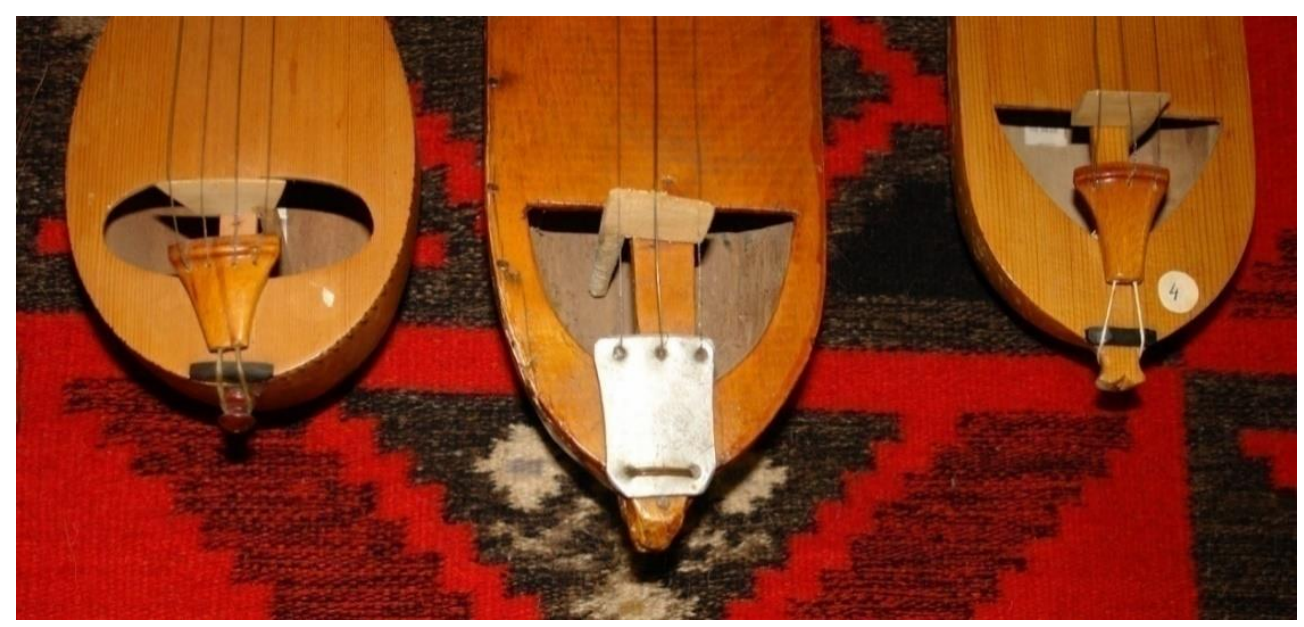

Fotoğraf 6. Kauşların ses delikleri, kuyruk ve eşik detayları (Komrat Müzesi, Gagauz Özerk Yeri).

Çalgının sap bölümü oldukça kısadır. Bunun ön yüzü, icrada parmakların ucunun dayandığı tuşe kısmını da oluşturmaktadır. Sapın üst bölümünde akort burgularının yer aldığı burguluk bölümü bulunmaktadır. Kauş’un burguluğu değişik formlarda yapılmaktadır. Bu formlar kimi zaman çokgen, kimi zamanda daire biçiminde olabilmektedir (Fotoğraf 1, 3, 4). Burguluk üzerinde yer alan akort burguları, burguluğun arka tarafından geçirilip, ön yüzünden çıkartılmaktadır. Burguların uçları yaklaşık 1-3 cm. kadar burguluğun üzerine taşmaktadır (Fotoğraf 4). Öndeki bu çıkıntıya teller sarılmaktadır.

Çalgının tellerini taşıyan ve kapak üzerinde yer alan köprüsü, genellikle akça ağaçtan yapılmaktadır. Köprünün bir tarafı candireği gibi uzatılarak ses deliğinin içine sokulmakta ve gövdenin içine temas ettirilmektedir (Fotoğraf 6).

Çalgının tellerinde farklı kalınlıklara sahip metal teller kullanılmaktadır.

Çalgının yayı, parmak kalınlığında bir ağaç ve at kılından yapılmaktadır. Kıllar yay ağacının iki ucuna çok gergin olmayacak şekilde bağlanmaktadır (Fotoğraf 1). Kauş icracısı yayı, keman ailesi çalgılarından farklı biçimde tutmaktadır. Batı çalgılarında yaylar üstten tutulurken, bu çalgıda icracı orta ve yüzük parmağını yay ağacı ile kıllar arasına sokmakta ve böylece yayı istenilen gerginliğe ayarlayabilmektedir (Fotoğraf 2, 7, 8).

Bu çalgının icrası hem tırnak yüzeyi, hem de parmağın etli kısmıyla yapılmaktadır. İlk tele (tiz ses veren) yandan tırnak yüzeyi ile temas edilerek sesler oluşturulurken, ikinci ve üçüncü tele parmağın etli olan iç kısmı bastırılarak icra gerçekleştirilmektedir. Dolayısıyla kauşun icrasında iki farklı tekniğin bir arada kullanıldığı görülmektedir. Çalgının ilk telinde ezgiler oluşturulurken, diğer tellerle ise bu ezgiye dem tutulmaktadır. 
İcracıların kauşu iki farklı pozisyonda tutarak çaldığı görülmektedir. Kimi zaman ayakta durarak (Fotoğraf 2), kimi zamanda sandalyeye oturup bir dizinin üzerine koyarak bu çalgının icrası yapılmaktadır (Fotoğraf 7, 8).

Çalgıda tellerinin akordu dörtlü veya beşli aralıkta yapılabilmektedir. Teller, Sol- Re-Sol veya $\mathrm{La}$ Mi-La notalarına akort edilmektedir8.

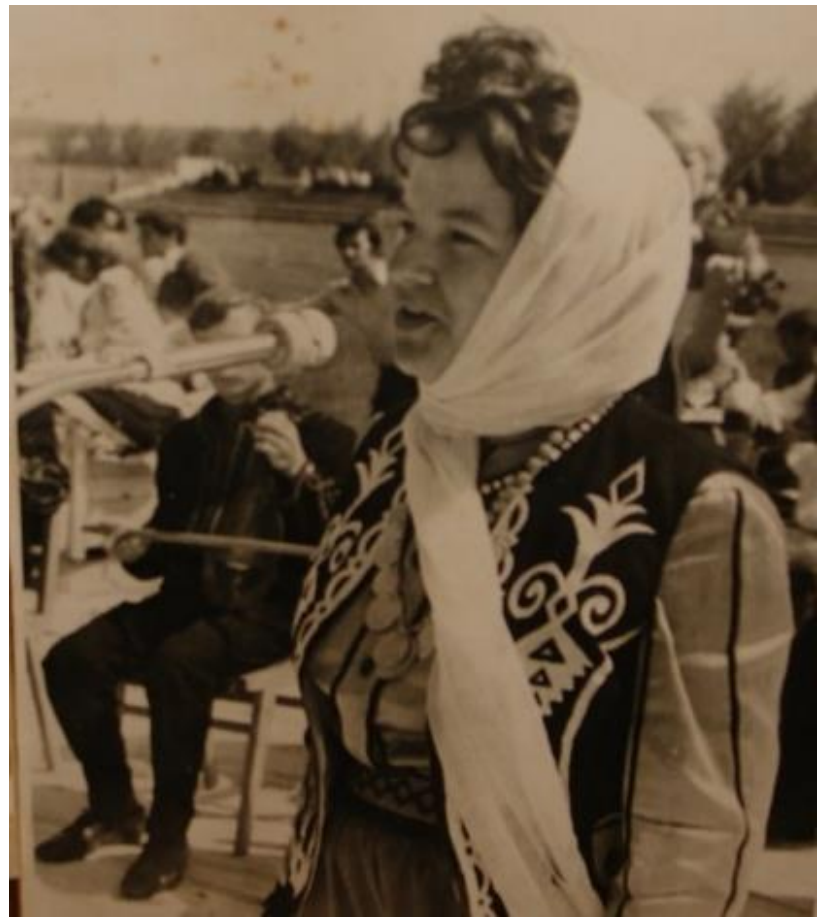

Fotoğraf 7. Kauşun diz üzerindeki icrası (Komrat Müzesi, Gagauz Özerk Yeri).

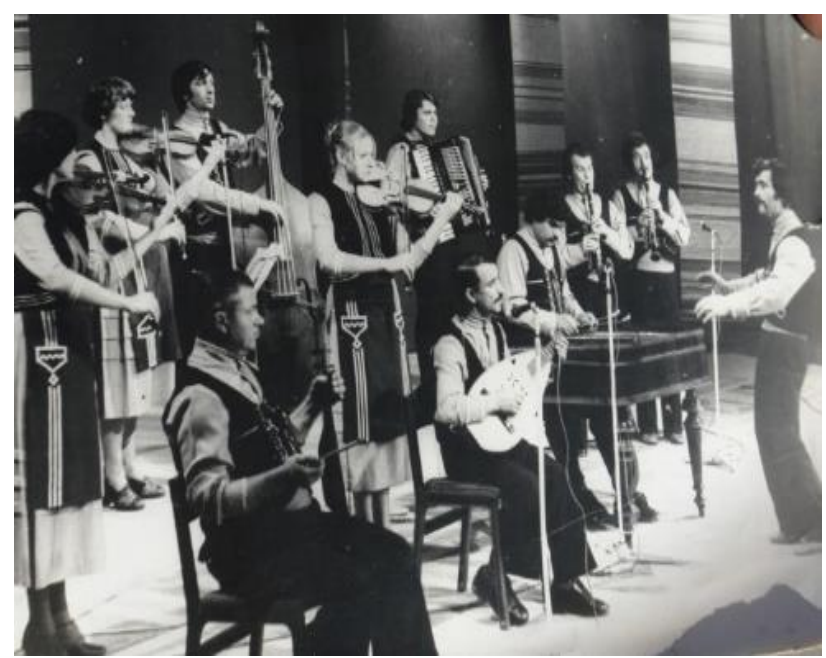

Fotoğraf 8. Kauş icracısı Görgi Görgiviç Stamatov (Komrat- Gagauz Özerk Yeri, 1978).

${ }^{8}$ Bu bilgiler 2012 yılında Moldova'nın Gagauz Özerk Yerinde yapılan araştırmalarda Constantin Ruşika, Pioty Petkoviç ve Topal Sergey'den alınmıştır. 


\section{SONUÇ VE ÖNERILLER}

Fiziki yapısı, tel sayısı ve icra tekniği itibariyle Anadolu'da Batı Toroslarda icra edilen Yörük kemanesine oldukça benzeyen kauş, Gagauzların önemli çalgıları arasında yer almaktadır. Geçmişte düğün ve eğlencelerin ana çalgılarından biri olan kauş, davul, kaval ve çığırtma ile beraber icra edilmiştir. Ancak 20. yüzyıl içerisinde kültür ve müzik anlayışında hızlı bir değişim yaşanması sebebiyle çalgının kullanımı giderek azalmıştır. Günümüzde ise bu çalgıyı icra eden ve yapanlara pek rastlanmamaktadır.

Kültürel bir miras olan müzik ve müzik aletlerinin korunması, yaşatılarak gelecek nesillere aktarılması önem arz etmektedir. Bu sebeple Gagauz müzik kültürünün kıymetli bir unsuru olan kauş çalgısının ivedilikle ele alınması ve yaygınlaştırılması son derece elzemdir. Yetkililer ve müzik alanında uzman kişiler bu çalg1 üzerinde durmalı, konservatuvar ve halk eğitimi merkezlerinde verecekleri eğitimler ile onu tekrar icra edilir hale getirmelidir. Bu kapsamda geleneksel çalgılar ile Gagauz halk ezgilerini seslendiren koroların kurulması ve yaygınlaştırılması da yerinde olacaktır.

\section{KAYNAKLAR}

Bulgar, S. (2004). Veysel Arseven (Vasili Öküzcü) 1919-1977 Biyografisi, Makaleleri ve Müzik Eserleri, Türksoy Yay:22, Ankara.

Çakır, M. (2007). Gagauzlar: İstoriya, Adetler, Dil hem Din, Kişinev 2007.

Gazimihal, M. R. (1958). Asya ve Anadolu Kaynaklarinda Iklı̆̆l, Ses ve Tel Yay. Ankara.

Gürdal, İ. (2009). “Kopuz ve Türk Dünyası Halk Çalgıları”, Musiki Dergisi, Şubat 2009, erişim adresi: www.musikidergisi.net Erişim Tarihi: 12.05.2016.

Karanfil, G. (2010). "Gagauzların Çalgı Adlarına Dair Bir Araştırma”, TURAN-SAM, C: 2, S: 8, Sonbahar.

Moşkov, V. (2004). Gagauzı Benderskogo uyezda, Kişinev.

Stamatoglu, G. (2002). Gagauzların Altın Kitabı, Komrat.

Gagauz Maddesi, Erişim Adresi:http://tr.wikipedia.org/wiki/Gagauzlar Erişim Tarihi: 05.25.2021. 


\section{KAYNAK KISŞILER}

Anna Görgivna STAMATOVA, (1929). Komrat (Gagauz-Moldova) doğumlu, Komrat'taki kauş icracısı Stamatov Görgi Görgiviç'in eşi.

Constantin RUŞİKA, (1952). Komrat (Gagauz-Moldova) doğumlu, müzisyen ve derlemeci.

İvan KIRIM, (1949). Komrat- Beşalma (Gagauz-Moldova) doğumlu, Beşalma Müzesinde görevli.

Görgi STAMATOGLU, (1946). Komrat (Gagauz-Moldova) doğumlu, araştırmacı - tarihçi.

Güllü KARANFIL, (1972). Komrat (Gagauz-Moldova) doğumlu, Gagauzeli Üniversitesinde dil bilimci - Türkolog.

Pioty PETKOVİÇ, (1964). Komrat (Gagauz-Moldova) doğumlu, müzisyen ve çalgı yapımcısı.

Topal SERGEY, (1968). Komrat (Gagauz-Moldova) doğumlu, müzisyen. 